\title{
Views of Parents for Difficulties in the Transition from Kindergarten to Primary School. The Role of Counseling and Future Trends in General and Special Education
}

\author{
Elli Samara, Vasiliki Ioannidi \\ Hellenic Open University, Patras, Greece \\ Email: samara.elli@ac.eap.gr, ioannidi.vasiliki@ac.eap.gr
}

How to cite this paper: Samara, E. and Ioannidi, V. (2018) Views of Parents for Difficulties in the Transition from Kindergarten to Primary School. The Role of Counseling and Future Trends in General and Special Education. Open Access Library Journal, 5: e5062.

https://doi.org/10.4236/oalib.1105062

Received: November 21, 2018

Accepted: December 18, 2018

Published: December 21, 2018

Copyright $\odot 2018$ by authors and Open Access Library Inc.

This work is licensed under the Creative Commons Attribution International License (CC BY 4.0).

http://creativecommons.org/licenses/by/4.0/

\begin{abstract}
The importance of collaboration between parents and teachers in the field of education has been recognized internationally with the significance of active parental engagement in school life being highlighted. Especially, a child's transition from Kindergarten to Primary School can be a life-changing experience not only for the child itself but also for its family. The present research was conducted in May 2018 with the school year having been completed in order to collect research data on parents' views about the difficulties they consider children face during their transition to Primary School. The research was based on structured interviews which can both be used as a qualitative and quantitative research methodology. In this research the participants were sixteen (16) parents of kindergarten children from five (5) Kindergartens in the municipality of Thessaloniki. The results of this research fill in a small gap, demonstrating that parents consider the transition from Kindergarten to Primary school important and are aware of the challenges their children could face during this period of development. School counseling could provide both help and encouragement to those parents properly preparing to support their children through this major life change and to assure themselves that they will cope with any future difficulties effectively.
\end{abstract}

\section{Subject Areas}

Education

\section{Keywords}

General and Special Education, Difficulties, Transition, Kindergarten, Primary School, Counseling 


\section{Introduction}

The importance of collaboration between parents and teachers in the field of education has been recognized internationally with the significance of active parental engagement in school life being highlighted, not only for enhancing children's development and achieving academic goals effectively but also developing communication between parents and their children [1] [2] [3] [4].

Hence, having been considered as a fundamental factor of positive influence in children's daily school life and particularly in special education, collaboration between schools and families is established as a continuous target, since education itself is an ongoing process [5]. Nevertheless, sustainable progress in education depends on the continued setting of specific targets, which allow the measurement and documentation of progress over time. Research has shown that schools should consider the wider progress made by pupils, which cannot be captured by narrow progress measures. Furthermore, research suggests that key measures are necessary including consistency in how support is delivered, and effective communication systems that help to maintain consistent approaches to support and allow for adaptation as part of the cycle of "assess, plan, do and review" [6].

Within this framework, it is no coincidence that creative interaction derived from the collaboration of parents with teachers has an impact on the learning process and the overall inclusion of children in schools. According to Henderson, Berla [7], parental involvement in children's education can significantly contribute to students' achievements with the completion of more school projects, building positive thinking mindsets and attitudes, improving quality of life and setting greater expectations but also ensuring their successful transition from the earliest childhood years through tertiary education.

The issue that arises based on the findings above is that the notion of parental engagement is often confounded with the notion of the interactive and dynamic relationship developed between the family and educational framework. However, the notion of parental involvement does not always require a direct parent-school partnership even though it is a prerequisite for building the relationship between both frameworks [8]. Building such a partnership has particular significance in the transition of every child to different grade levels with the one of Compulsory Education being considered the most difficult and stressful environment.

Especially, a child's transition from Kindergarten to Primary School can be a life-changing experience not only for the child itself but also for its family.

Given the fact that the concept of transition involves complex changes, which can affect both the individual and his environment, to attain a smooth transition from Kindergarten to Primary School a proper preparation of the child is required. To achieve this, time and partnerships are necessary to support this complex process. 


\section{Research}

\subsection{Objective}

The present research was conducted in May 2018 with the school year having been completed in order to collect research data on parents' views about the difficulties they consider children face during their transition to Primary School [9].

\subsection{Methodology}

For the data collection, research was based on structured interviews which can both be used as a qualitative and quantitative research methodology. Questions are predetermined and asked in a standardised order without providing fixed answers in advance. Although it is quite a demanding method, structured interviews are popular due to the benefits they offer to the researchers. One benefit is the collection of specific information, such as the participants' personal views, while another advantage is that in personalised discussions the researcher has the overall control. All responses are evaluated using the same standards for acceptable answers with the ability to reject erroneous ones due to time restrictions, indifference and other reasons. Furthermore, participants can pose questions or ask for clarifications in case of unclear questions [10].

In this research the participants were sixteen (16) parents of kindergarten children from five (5) Kindergartens in the municipality of Thessaloniki.

Statistical analysis was performed with the IBM SPSS Statistics 22 software.

\section{Results \& Discussion}

\subsection{Personal Data}

In this research the majority of the participants were aged over 35 years while half of them were between 35 and 40 years of age. This finding is no surprising since several factors (such as women's different roles, getting married at a late age, the childcare problem and the high cost of upbringing) lead to delayed childbearing (Graph 1).

This particular finding combined with the answers regarding the participants' level of education reveals the trend in recent years, according to which the idea of having a family is no longer a primary goal and delayed parenthood is more common compared to previous years. The following chart shows that the majority of the participants have completed tertiary education $(56.25 \%)$ while the minority continues on to a postgraduate or a doctoral program. The percentages of the participants who have only completed Compulsory Education (6.25\%) or Secondary Education (18.75\%) are quite small (Graph 2).

In the present research only mothers of 16 kindergarten children participated. This is inextricably linked to the profession of both parents. As illustrated in the following graph unemployed mothers reach $50 \%$. It is equally important to mention that there are some mothers who only work for a few hours. The percentage 


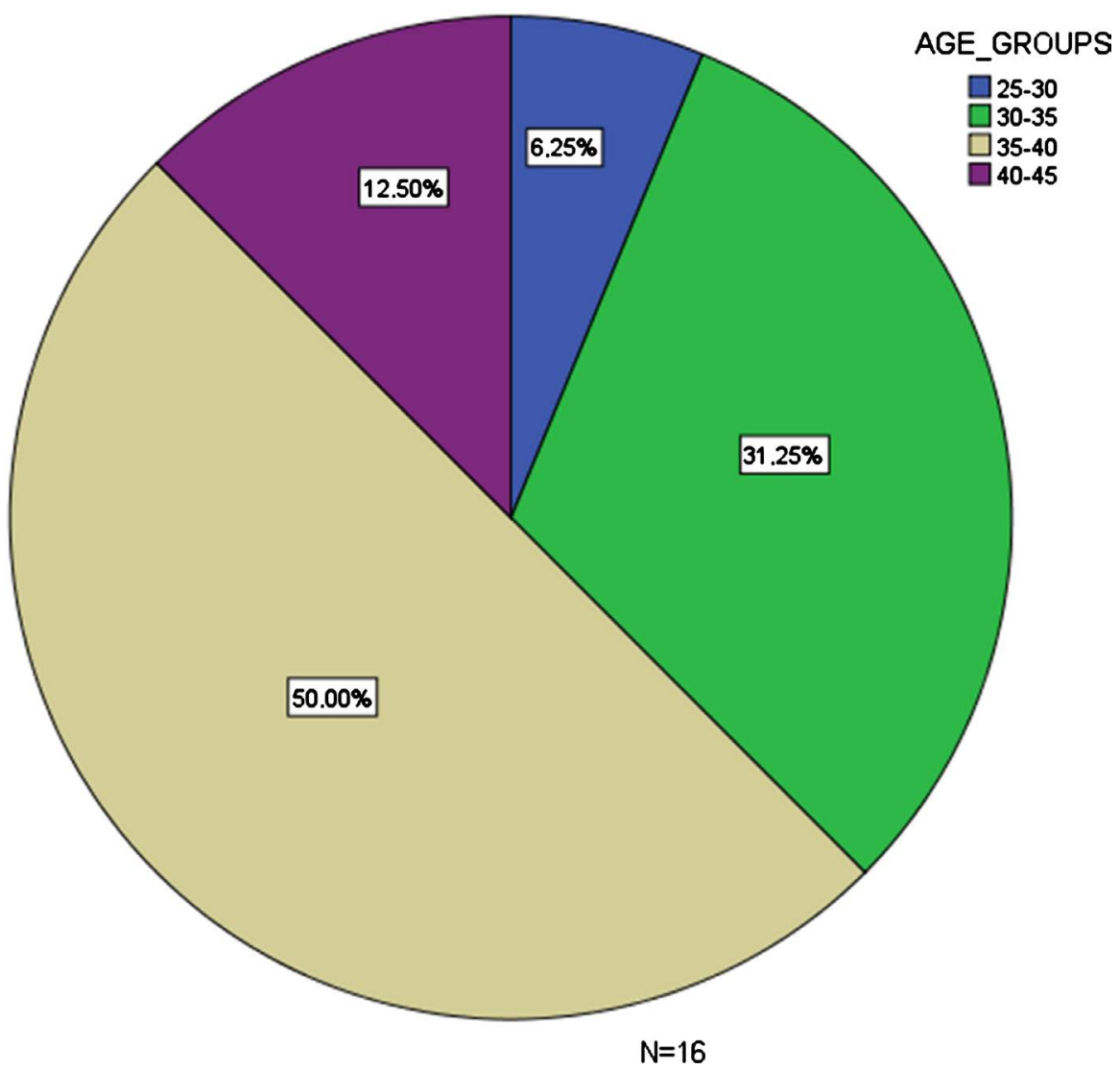

Graph 1. Participants by age.

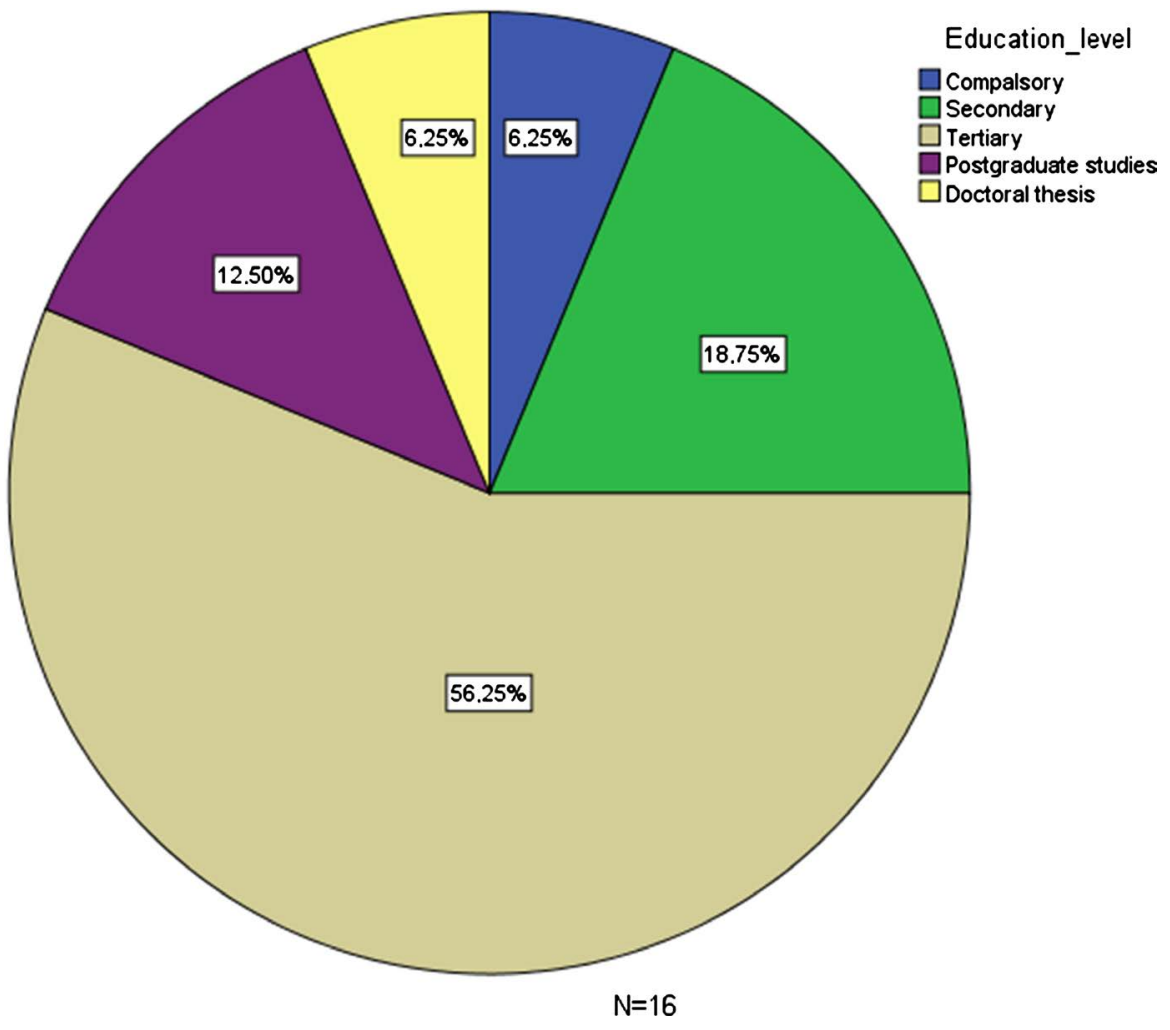

Graph 2. Participants' education level. 
of mothers with full-time employment is quite small (18.75\%). The results show the dominant culture portrayal of family-oriented women, while their partners remain active in the job market. However, in a contemporary society where women are interested in joining the paid work force, these particular results could actually reveal the contemporary socio-economic status of our country (Graph 3).

In contrast to the mothers, their partners have full-time employment with the majority (56.25\%) working for more than $40 \mathrm{hrs}$ per week. However, this finding is no surprising being compared with the jobs shortage or the mothers' part-time employment. At least one parent is forced to work full-time in order to afford all the family's expenses (Graph 4).

\subsection{Transition}

The participants were asked to evaluate how important the transition from Kindergarten to Primary school is. The majority (87.5\%) considers this transition essential. However, it is striking to see, based on the references used so far, that there is a small number of mothers who believe the opposite (Graph 5).

There have been several different responses to the question of whether transition to Primary school is a cause for concern or anxiety. $25 \%$ of the participants experience anxiety to the idea of their children transitioning to a different environment with rules, a specific schedule and less play. $18.75 \%$ state that the other children's behavior is the primary source of their anxiety, which is not particularly surprising, since bulling has been a growing problem for contemporary

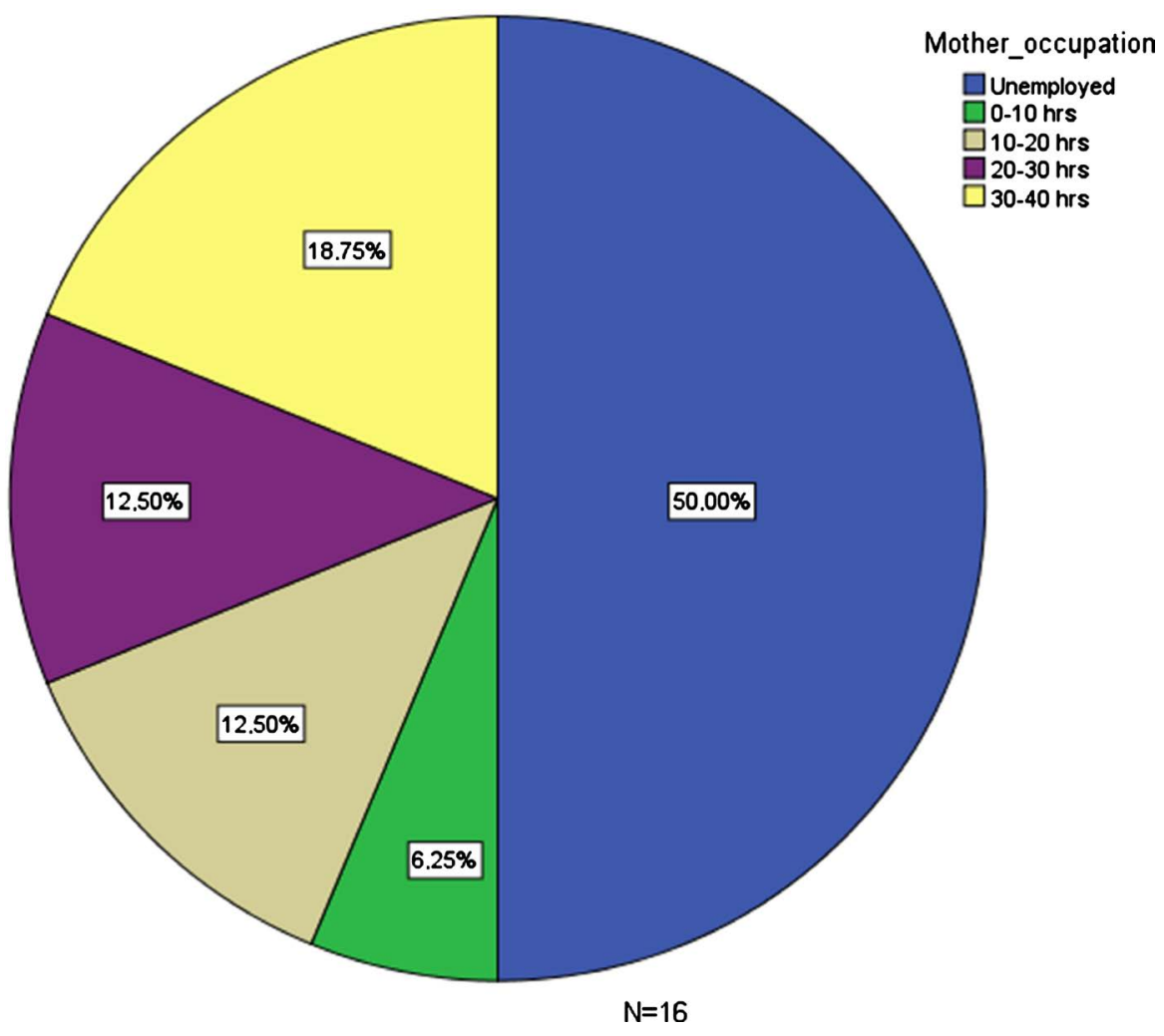

Graph 3. Mother's occupation. 


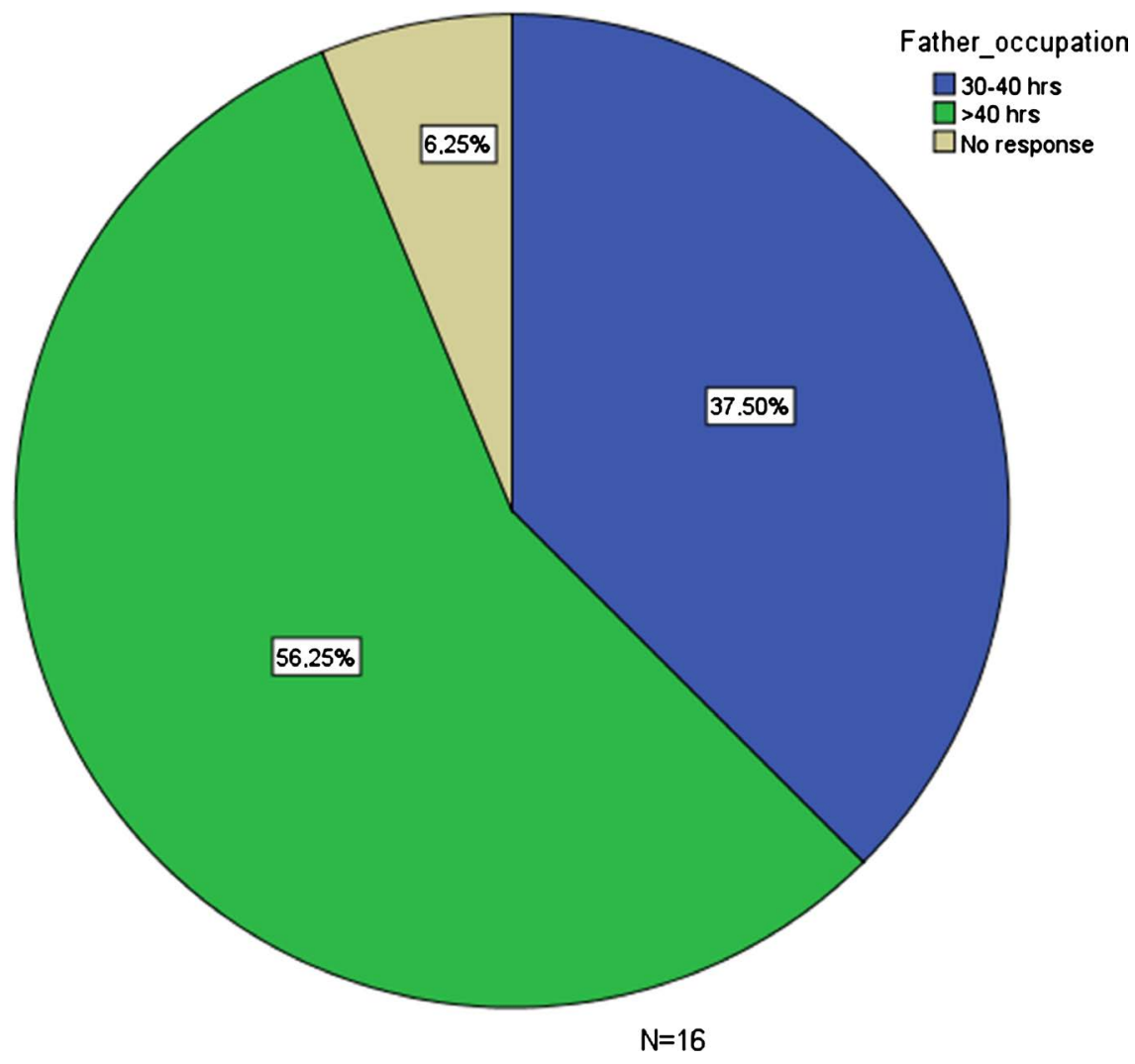

Graph 4. Father's occupation.

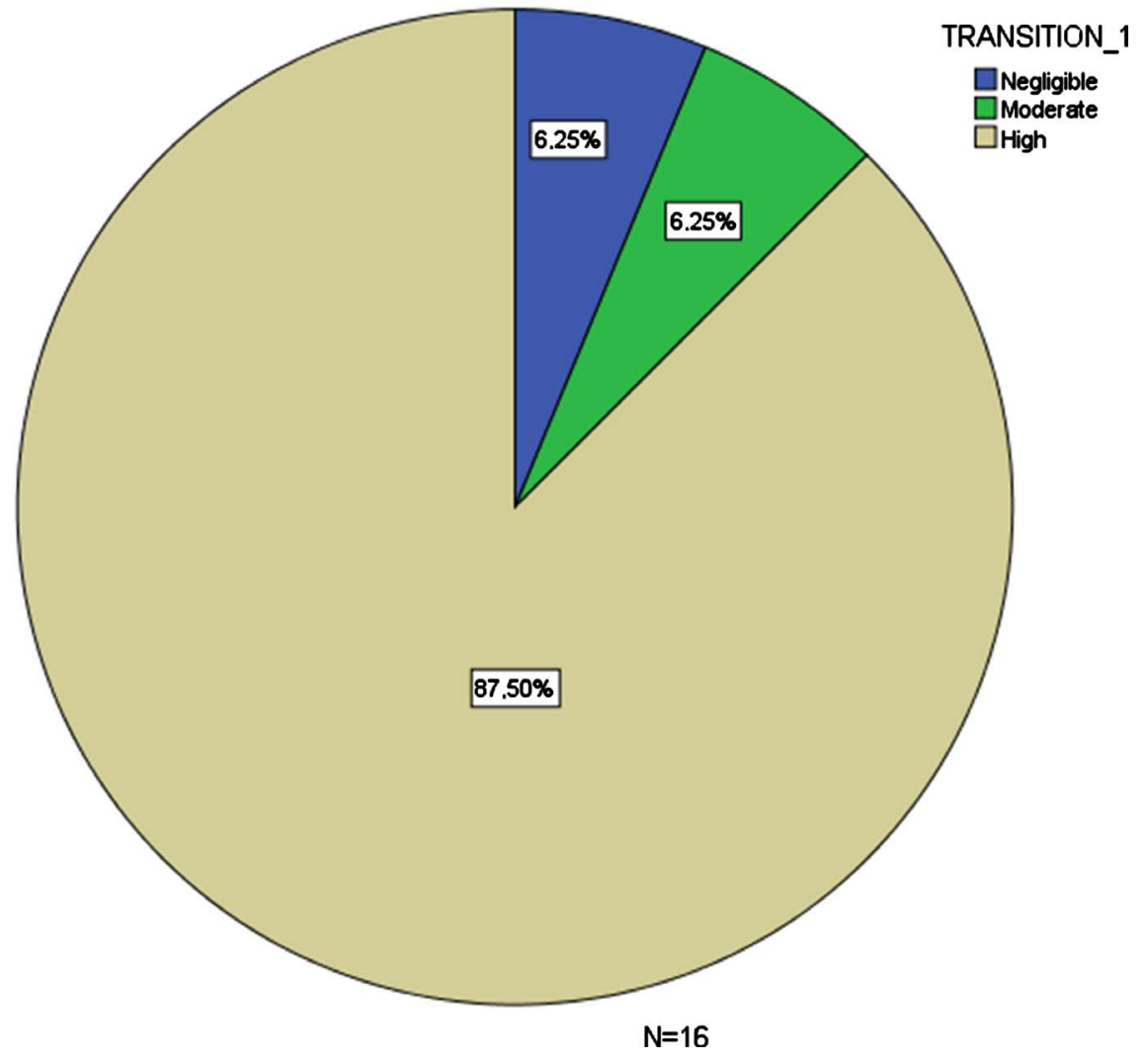

Graph 5. Importance of transition. 
society. Worthy of attention is the large percentage of participants (31.25\%) that do not regard their children's transition from Kindergarten to Primary school as a stressful experience. While interpreting these answers, parents' lack of awareness should be taken into consideration. Moreover, it could also be their positive way of thinking and tackling the transition or even the simple idea that it is nothing but the natural development of their children and consequently their lives (Graph 6).

Quite encouraging is the fact that most participants (81.25\%) are informed about the difficulties their children may face during their transition to Primary school (Graph 7).

A quarter of the participants referred to the rules and the schedule as factors that could have an impact on their children during their transition to Primary school, since they are both different from what they have been used to. It is important to note that $31.25 \%$ of the respondents mentioned the behavior of other children, while $18.75 \%$ commented on the teacher their children may have. It is indisputable that the relationships children build with their fellow students or their teacher can play an essential role. However, all these references show the mothers' tendency to think that third-party behaviors are considered to be more important than ours. Parents should properly prepare their children for this transition in order for the latter to be more familiar with certain things, such as active participation, harmonious co-existence and problem solving. In this case, it would be more likely to enable themselves to tackle peers' disruptive behaviors and develop positive and healthy relationships with their teachers (Graph 8).

There were several responses to the question regarding parents' expectations

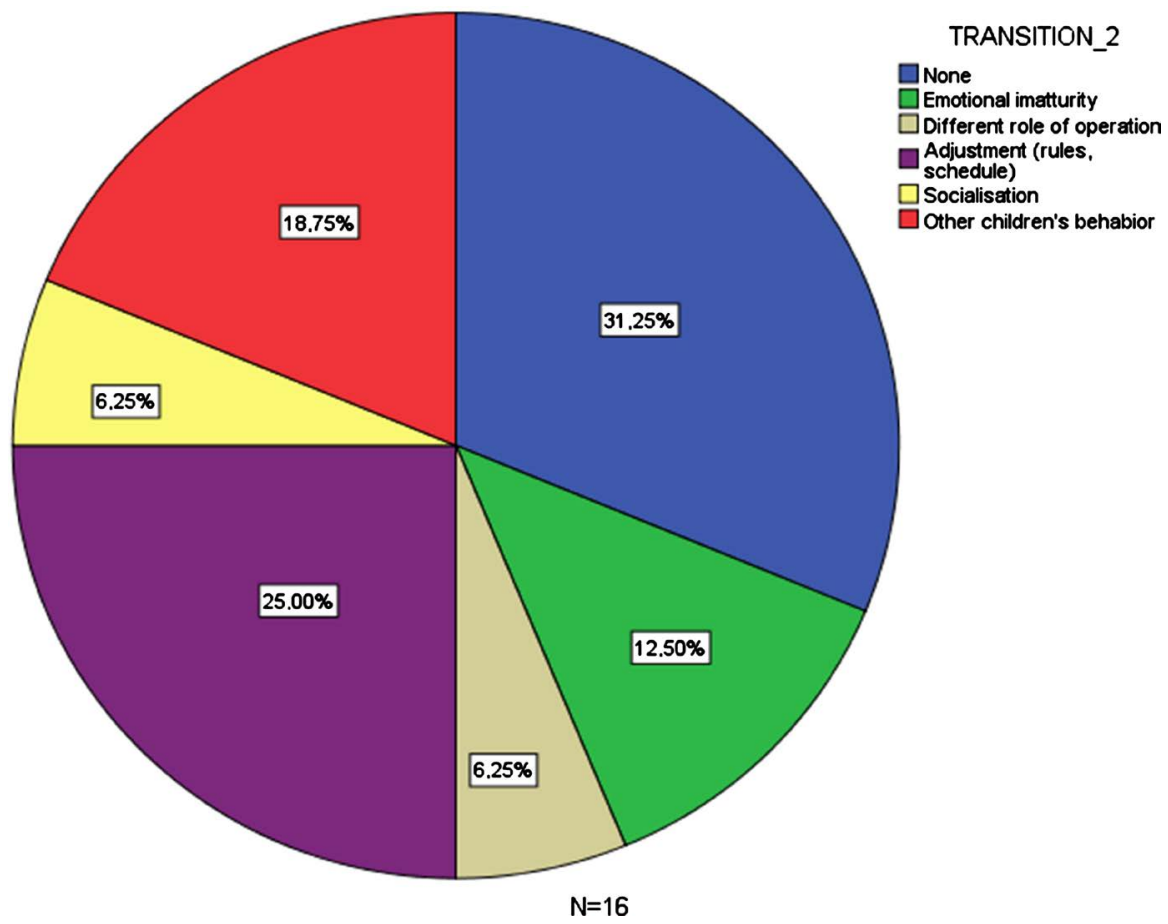

Graph 6. Sources of anxiety. 


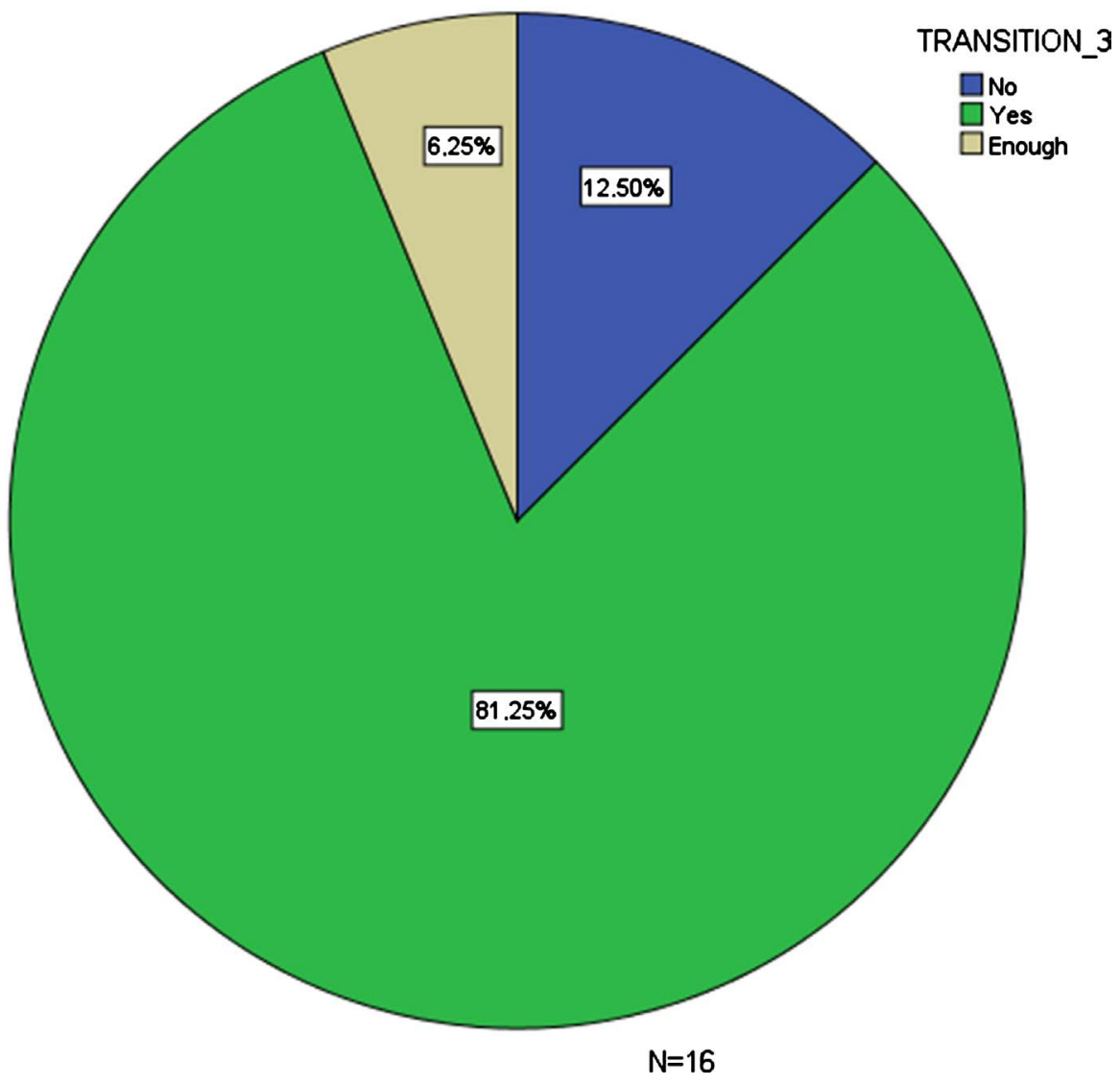

Graph 7. Awareness of potential difficulties.

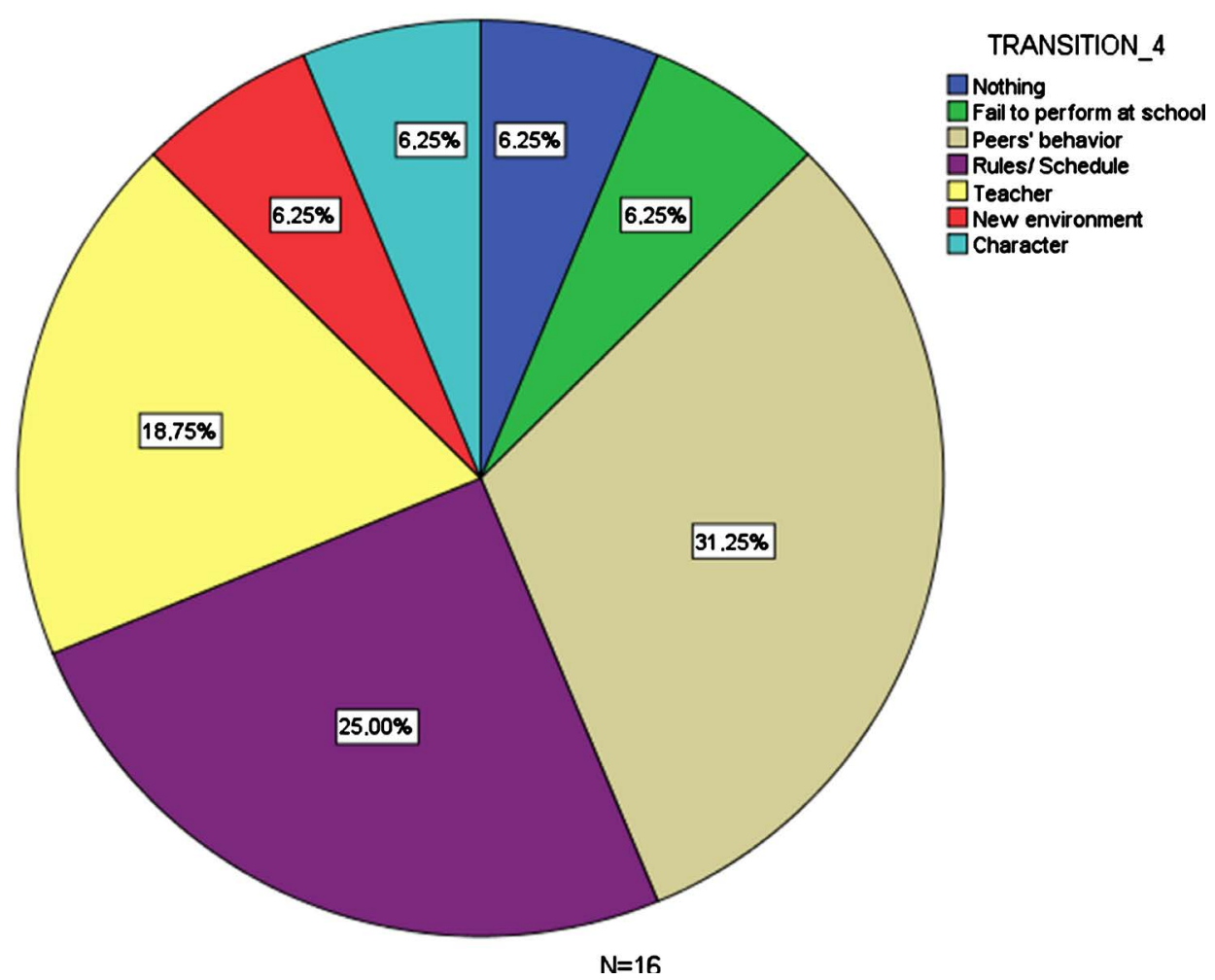

Graph 8. Potential difficulties during transition. 
of their children's primary schools. A quarter of the participants expect from schools to help their children think fondly of the school they are attending and not develop any negative feelings towards it. 18.75\% expect from primary schools to encourage children to be more independent. According to the references, during their transition to primary schools, the more independent children are, the more capable of tackling daily tasks effectively they would feel. Another $18.75 \%$ stated that the only expectation they have is schools make their children happy. It is striking to note that a similar number of the participants do not have any expectations whatsoever. There are different ways we could interpret the later responses. On the one hand, they show that parents may not have considered the expectations they should have, while, on the other hand, they possibly reveal parents' simple thinking about their children's new daily life or even a lack of trust in the system (Graph 9).

The participants were also required to evaluate whether counseling would be useful or helpful regarding their children's transition from Kindergarten to Primary school. It was quite encouraging to see that the majority $(68.75 \%)$ responded positively. Counseling plays an essential role and could offer parents significant assistance in their effort to properly prepare their children. It was striking to note that $12.50 \%$ responded negatively, while $18.75 \%$ believe that counseling could help some parents or under certain circumstances (Graph 10).

\section{Conclusions \& Suggestions}

Historically, the issue of transition has been an important landmark in the history of educational reforms. Throughout the $20^{\text {th }}$ century not only there has been

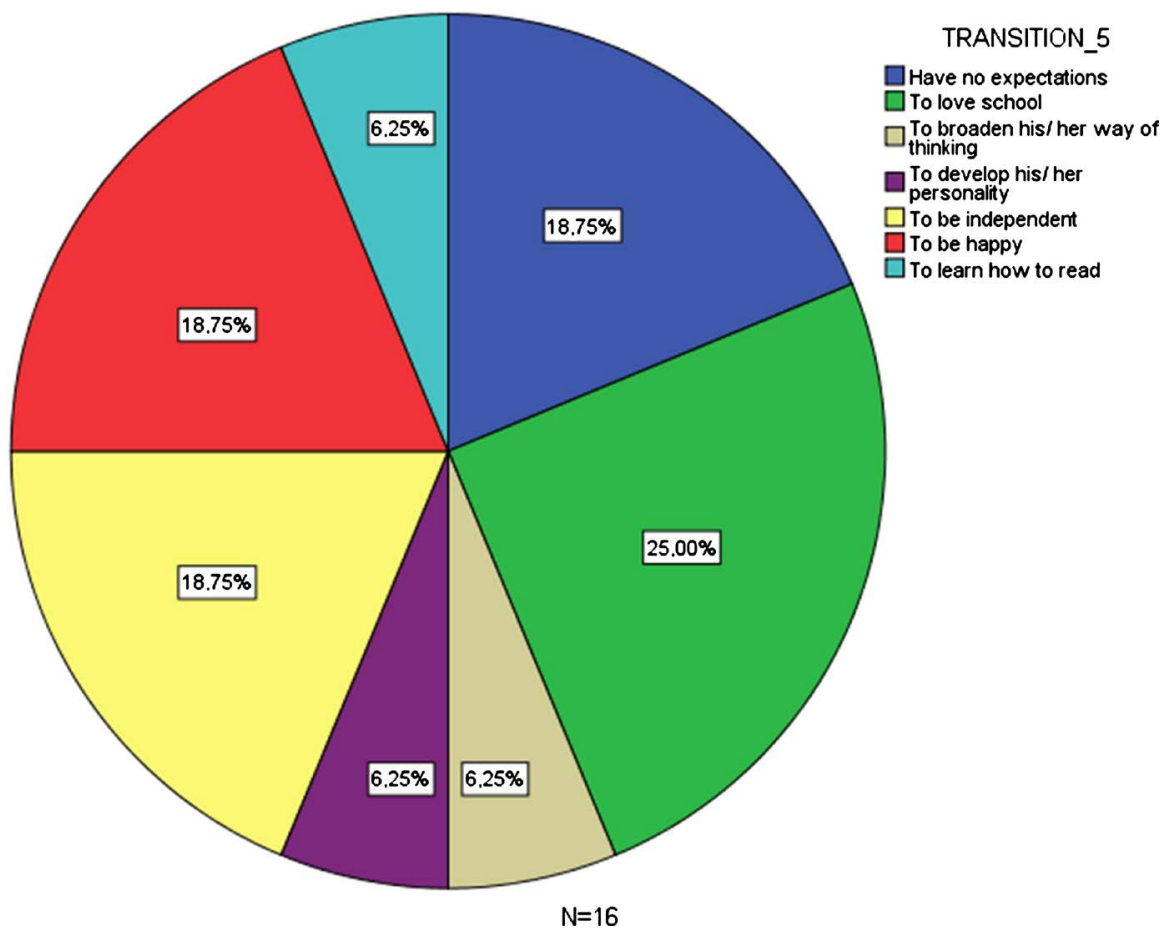

Graph 9. Expectations of primary schools. 


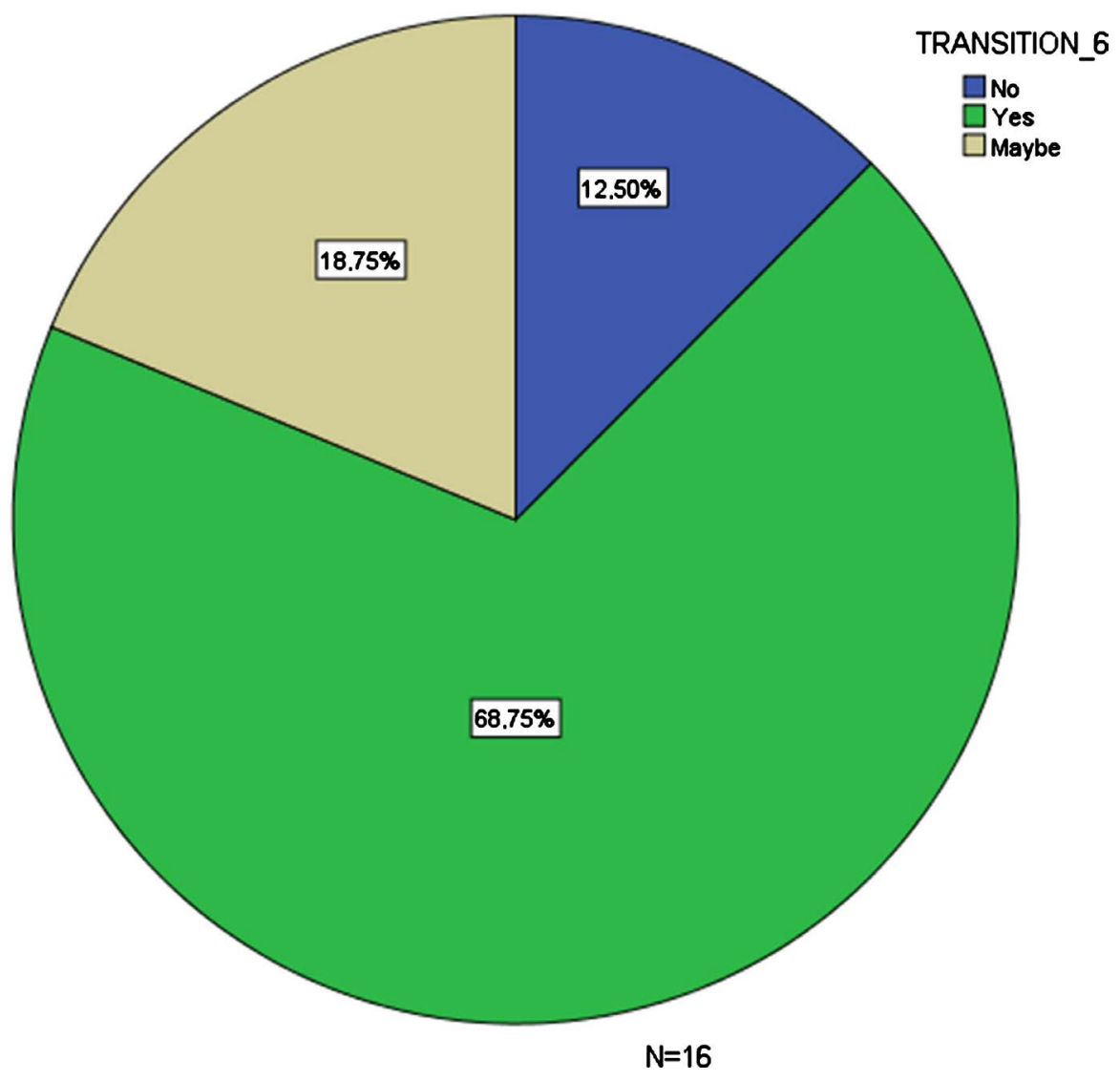

Graph 10. The importance of counseling.

an immense interest in the qualitative development of both sub-levels, the Kindergarten and the Primary school, respectively, but also this time period is defined as the advent of reform initiatives for "bridging the gap". It should be noted that the said bridging is pursued with the organic connection and the collaboration of both educational environments, which enable the attainment of targets, objectives, contents, teaching approaches and quality enhancement of teacher education [11].

On the other hand, parent-teacher communication is essential if a collaborative relationship is to be established. The outcome is the enhancement of the whole child, not only educationally but also socially and emotionally. However, who is responsible for initiating and maintaining this relationship? What elements does each side contribute? How will this assist the classroom, as well as the home? What are some of the potential barriers to the communication process? How to create a collaborative relationship between parents, and school personnel? These questions are to be examined and answered by the latest literature as well as other ways in which this relationship can be an efficacious one and serve to benefit the student, the family, the classroom and the school community as a whole [12].

On this basis, the results of this research fill in a small gap, demonstrating that parents consider the transition from Kindergarten to Primary school im- 
portant and are aware of the challenges their children could face during this period of development. Such various potential challenges are indicated by the participants in the present research while the majority of whom have acknowledged the importance of school counseling. Nonetheless, this transition process can be quite stressful for parents suggesting a lack of counseling support. School counseling can help parents prepare themselves for the upcoming changes in their everyday life as well as prepare their children in order to be able to cope with the new challenges and conditions that will shape their everyday life. Parents always do what they consider is best for their children. However, not all parents are in a position to comprehend the role they can play in certain aspects of their children's lives. Some parents cannot understand how important it is to provide their children with the ability to take initiatives, make decisions, resolve simple daily life problems, take over responsibilities, and they do not even consider it necessary from a young age. Counseling support services could assist parents with properly preparing their children for this transition by making the latter more independent and enabling them to suitably adjust and respond in the new and different environment accordingly. Additionally, counseling not only could fortify the relationship between schools and families by offering parents a whole picture of the role schools have, but also the significance of an active and constructive family engagement in children's education.

Summing up, a family-school relationship traditionally constitutes the framework for theoretical dialogue and research interest, having been correlated with the improvement of education quality, promotion of academic attainment but mainly children's achievements and, in a broader sense, the reinforcement of both family and school's effectiveness acting as agents of conduct and socialization [8]. Thus, school counseling could provide both help and encouragement to those parents properly preparing to support their children through this major life change and to assure themselves that they will cope with any future difficulties effectively. It has been noted that schools need to improve services and interventions regarding parent orientation, counseling and support in different aspects and frameworks of special education [5], where independence and self-esteem are taught to enable children tackle any disability or special educational need they may have, both congenital or acquired [13].

As aptly noted "parents must have an active role to develop a shared vision for their children and follow through on objectives to achieve the shared vision. Parents and school personnel must take a role in implementing a strategic collaborative plan and be accountable for their role in the process" [12]. This concerns General and Special Education.

\section{Conflicts of Interest}

The authors declare no conflicts of interest regarding the publication of this paper. 


\section{References}

[1] Steh, B. and Kalin, J. (2011) Building Partner Cooperation between Teachers and Parents. CEPS Journal, 1, 81-101.

[2] Henderson, A. and Mapp, K. (2002) A New Wave of Evidence. The Impact of School, Family, and Community. Connections on Student Achievement. Annual Synthesis. SEDL_Advancing Research, Improving Education. National Center for Family \& Community. Connections with Schools, Austin, Texas.

[3] Sapungan, M.-G. and Sapungan, M.-R. (2014) Parental Involvement in Child's Education: Importance, Barriers and Benefits. Asian Journal of Management Sciences \& Education, 3, 42-48. https://www.researchgate.net/publication/283539737_Parental_Involvement_in_Ch ild\%27s_Education_Importance_Barriers_and_Benefits

[4] Tsimpidaki, A. (2007) Paidi me idikes anages, oikogeneia kai sxoleio. Mia sxesi se allilepidrasi. [A Special Needs Child, Family and School. An Interactive Relationship.] Atrapos, Athens.

[5] Samara, E. (2016) H sinergasia anamesa se daskalous idikis agogis kai goneis paidion me varies anapiries. [The Collaboration between Special Educators and Parents of Severely Disabled Children.] In: Papadatos, I., Polyhronopoulou, St. and Bastea, A., Eds., Proceedings of the $6^{\text {th }}$ Panhellenic Conference of Science, Education and Special Education, vol. B', 1152-1167.

[6] Belli, C. (2018) An Exploration into How the Impact of Interventions for Pupils with Special Educational Needs Can Be Sustainable and Support Long Term Progress. SFL, 33, 5-22.

[7] Henderson, A. and Berla, N., Eds. (1994) A New Generation of Evidence. The Family Is Critical to Student Achievement. National Committee for Citizens in Education, Washington DC.

[8] Penteri, E. and Petrogiannis, K. (2013) Sindesi sxoliou-ikogeneias kai to zitima tis metaxis tous sinergasias: Kritiki parousiasi vasikon theoritikon modelon. [The Family-School Connection and Their Collaboration Issue: A Critical Presentation of Basic Theoretical Models.] Research in Education, 1, 2-26.

[9] Samara, E. and Ioannidi, V. (2018) Aorates dyskolies kata th metavash apo to Nhpiagvgeio sto Dhmotiko sxoleio. O rolos tns Symvoyleytikhs. [Invisible Difficulties in the Transition from Kindergarten to Primary School. The Role of Counseling.] Presentation in the $7^{\text {th }}$ Panhellenic Congress of Counseling Psychology, University of Thessaly, Hellenic Psychological Society, Volos, 8-11/11/2018.

[10] Cohen, L., Manion, L. and Morrison, K. (2007) Research Methods in Education. Metaixmio, Athens. (In Greek) https://doi.org/10.4324/9780203029053

[11] Sidiropoulou, T., Dimitriadi, E. and Ralli, A, (2011) metavasi tou mikrou paidiou se diaforetika ekpaideutika perivallonta. [The Transition of a Young Child to Different Educational Environments.] Pedagogical Speech, 1, 53-83.

[12] McCarthy, P., Brennan, L. and Vecchiarello, K. (2011) Parent -School Communication in the Inclusive Classroom: A Comprehensive Model of Collaboration in Education. International Journal of Humanities and Social Science, 1, 55-60. http://www.ijhssnet.com/journals/Vol_1_No_15_Special_Issue_October_2011/7.pdf

[13] Karvelas, M. and Ioannidi, B. (2018) Anapiries kai Nevrologika syndroma: Syndroma ton lovon kai tou fliou ton egefalikon imisferion. Symvouleutiki ipostirixi. [Disabilities and Neurological Syndromes: Lobe and Cerebral Cortex Syndromes. Counseling Support.] e-Journal of Science \& Technology, e-JST, 13, 37-49. 